\title{
Dismenore dan Kecemasan pada Remaja
}

\author{
Handayani, Indria Laksmi Gamayanti, Madarina Julia \\ Bagian Ilmu Kesehatan Anak Fakultas Kedokteran UGM/RSUP Dr Sardjito, Yogyakarta
}

\begin{abstract}
Latar belakang. Prevalensi dismenore cukup tinggi pada remaja. Dampak yang ditimbulkan dari dismenore adalah penurunan aktifitas sehari-hari sampai memerlukan terapi. Faktor risiko dismenore tidak hanya berkaitan dengan faktor fisiologis tapi juga faktor psikologis termasuk kecemasan

Tujuan. Mengetahui prevalensi dismenore, prevalensi kecemasan tinggi, dan hubungan antara kecemasan dan dismenore pada remaja di kota Surakarta.

Metode. Rancangan penelitian adalah cross sectional. Sembilan puluh subyek remaja putri yang memenuhi kriteria inklusi dan eksklusi mengikuti penelitian.

Hasil. Prevalensi dismenore pada remaja di kota Surakarta 87,7\%. Delapan puluh tujuh koma tujuh persen remaja tetap beraktivitas saat mengalami dismenore dan 12,2\% menggunakan analgetik untuk mengurangi keluhan dismenore. Prevalensi skor kecemasan tinggi pada remaja di kota Surakarta 47,8\%. Rerata skor VAS 4,1 2 2,2, dan rerata skor TMAS 22,6 $\pm 5,7$. Pada uji chi square, tidak didapatkan hubungan antara skor kecemasan yang tinggi dengan skor dismenore (RP 1,1 (IK 95\% 0,4-2,8, Pearson chi square = 0,05, $\mathrm{p}=0,82$ ). Hasil uji korelasi Spearman antara skor VAS dan skor TMAS diperoleh nilai 0,04, p=0,74. Berat ringannya dismenore tidak mempengaruhi jumlah subyek yang mencari pertolongan kesehatan (RP 4,1 (IK 95\% 0,5-34), p=0,28).

Kesimpulan. Prevalensi dismenore pada remaja di kota Surakarta cukup tinggi, namun berat ringannya dismenore tidak mempengaruhi subyek untuk mencari pertolongan kesehatan. Faktor informasi menstruasi, persepsi dismenore, dan karakteristik kepribadian diduga terkait dengan perilaku pencarian pertolongan kesehatan terkait dismenore remaja. Sari Pediatri 2013;15(1):27-31.
\end{abstract}

Kata kunci: dismenore, kecemasan, perilaku pencarian pertolongan kesehatan

ismenore adalah menstruasi yang disertai dengan rasa nyeri. ${ }^{1}$ Dismenore terjadi karena pelepasan prostaglandin yang berlebihan mengakibatkan kenaikan

\footnotetext{
Alamat korespondensi:

Dr. Handayani, Sp.A. Bagian Ilmu Kesehatan Anak, Fakultas Kedok teran Universitas Gadjah Mada - RSUP Dr Sardjito, Yogyakarta. Jl Kesehatan no.1, Sekip, Yogyakarta. Tel. (0274) 587333. E-mail: myhanyh@yahoo.com.
}

kontraksi uterus sehingga terjadi rasa nyeri saat menstruasi. Berdasarkan patofisiologi yang mendasari, ada dua tipe dismenore, yaitu dismenore primer (dismenore tanpa kelainan organik pada daerah pelvis), yang sering ditemui pada remaja, dan dismenore sekunder (dismenore dengan kelainan organik pada daerah pelvis seperti endometriosis dan mioma). ${ }^{2}$

Data mengenai dismenore sebagai permasalahan remaja belum banyak didapatkan di negara kita. Di 
negara lain, prevalensi dismenore cukup tinggi terjadi pada remaja. ${ }^{3,4}$ Dilaporkan dismenore akan berdampak pada aktivitas sehari-hari remaja seperti dalam studi di Cina, sebanyak 92,4\% subyek menderita dismenore ringan - berat, 39,9\% harus absen dari sekolah dan 49,8\% menggunakan analgetik 1-6 kali per siklus. ${ }^{5}$

Kecemasan didefinisikan sebagai status fisiologik dan psikologik yang mencakup karakteristik kognitif, somatik, emosi, dan tingkah laku yang membentuk perasaan uneasiness, apprehension, or worry. ${ }^{6}$ Kecemasan terdapat pada setiap individu dan diperlukan untuk pertahanan diri manusia terhadap stres. ${ }^{7}$ Faktor psikologi seperti kecemasan, depresi, pengalaman buruk seperti kejadian pelecehan seksual di masa lalu, dan stressor psikososial lain diyakini menjadi salah satu faktor risiko dismenore selain faktor fisiologi seperti kenaikan hormon prostaglandin dan kenaikan hormon vasopressin yang memengaruhi kontraksi otot uterus pada saat menstruasi. ${ }^{4,8}$

Tujuan dari penelitian untuk mengetahui prevalensi dismenore pada remaja, prevalensi kecemasan pada remaja, dan mengetahui hubungan kecemasan dengan dismenore pada remaja di kota Surakarta.

\section{Metode}

Penelitian observasional dengan rancangan cross sectional. Pengambilan sampel dilakukan secara consecutive dengan menggunakan kuesioner yang dilakukan sejak Januari 2011. Subjek penelitian adalah siswi SMP kelas 3 di Surakarta yang sudah menstruasi teratur, minimal dalam 6 bulan terakhir sebelum penelitian dilakukan, tidak menderita penyakit kronik atau sedang dalam pengobatan lama suatu penyakit, dan bersedia mengikuti penelitian. Kuesioner penelitian berisi data identitas subyek, penilaian menstruasi, penilaian tingkat dismenore dengan skor VAS (Visual Analog Scale), penilaian tingkat kecemasan dengan skor T-MAS (Taylor Manifest Anxiety Scale). Uji validaitas dan reliabilitas dari skor T-MAS dilakukan pada 30 siswi SMP 17 Surakarta. Data kualitatif diambil dengan cara interview pada sebagian subyek penelitian. Ethical clearance didapatkan dari Komite Etik Fakultas Kedokteran Universitas Gadjah Mada/RSUP dr Sardjito Yogyakarta dan semua subyek penelitian diminta informed consent yang ditandatangani orangtua/wali siswi yang bersangkutan.

Uji statistik menggunakan analisis deskriptif untuk mengetahui karakteristik subyek penelitian, dan analisis bivariat dengan uji chi square atau uji Fisher dan uji korelasi Spearman. Tingkat kemaknaan yang digunakan adalah $\mathrm{p}<0,05$ dengan interval kepercayaan (IK) $>95 \%$.

\section{Hasil}

Sembilan puluh subyek didapatkan memenuhi kriteria inklusi dan eksklusi. Karakteristik data dasar subyek penelitian tertera pada Tabel 1. Prevalensi dismenore pada remaja SMP di kota Surakarta didapatkan $87,7 \%$. Hampir sebagian besar remaja $(87,8 \%)$ tetap melakukan aktivitas sehari-hari saat terjadi dismenore, dan $12,2 \%$ remaja menggunakan obat analgetika untuk mengurangi rasa nyeri saat menstruasi. Rerata skor TMAS didapatkan 22,7 $\pm 5,7$ dan rerata skor VAS didapatkan 4,1 $\pm 2,2$.

Pada Tabel 2, hasil uji chi square tidak didapatkan hubungan antara kecemasan dengan dismenore (Pearson chi square $=0,05, \mathrm{p}=0,82$ ). Diperoleh nilai RP 1,1 (IK 95\% 0,4-2,8). Uji korelasi Spearman antara skor VAS dan skor TMAS diperoleh nilai 0,04 dengan $\mathrm{p}=0,74(\mathrm{p}>0,05)$, yang berarti terdapat nilai korelasi positif antara skor VAS dan TMAS dengan kekuatan korelasi yang lemah dan tidak bermakna secara statistik. Disimpulkan dari uji Fisher exact test, berat ringannya

Tabel 1. Karakteristik subyek n=90

\begin{tabular}{lc}
\hline Variabel & $\mathrm{n}(\%)$ \\
\hline Frekuensi nyeri (n) & \\
Tidak pernah & $12(13,3)$ \\
Jarang & $34(37,8)$ \\
Sering & $44(48,9)$ \\
Perilaku (n) & \\
Tetap aktivitas & $79(87,8)$ \\
Minum obat & $11(12,2)$ \\
Ijin sekolah & 0 \\
Dismenore (n) & \\
Tidak & $12(13,3)$ \\
Ringan & $13(14,4)$ \\
Sedang & $57(63,3)$ \\
Berat & $8(8,9)$ \\
Kecemasan (n) & \\
Rendah & $47(52,2)$ \\
Tinggi & $43(47,8)$ \\
\hline
\end{tabular}


Tabel 2. Hubungan antara kecemasan dan dismenore

\begin{tabular}{lccc}
\hline \multirow{2}{*}{ Kecemasan } & \multicolumn{2}{c}{ Dismenore $(\mathrm{n})$} & \multirow{2}{*}{ Total } \\
\cline { 2 - 4 } & Tidak-ringan & Sedang-berat & \\
\hline Rendah & 13 & 34 & 47 \\
Tinggi & 11 & 32 & 43 \\
\hline Total & 24 & 66 & 90 \\
\hline
\end{tabular}

Tabel 3. Dismenore dan perilaku mencari pertolongan kesehatan

\begin{tabular}{lccc}
\hline \multirow{2}{*}{ Derajat dismenore } & \multicolumn{2}{c}{ Perilaku mencari pertolongan kesehatan } & \multirow{2}{*}{ Total } \\
\cline { 2 - 3 } & Tetap aktivitas & Minum obat & \\
\hline Tidak dismenore - dismenore ringan & 23 & 1 & 24 \\
Dismenore sedang - berat & 56 & 10 & 66 \\
\hline Total & 79 & 11 & 90 \\
\hline
\end{tabular}

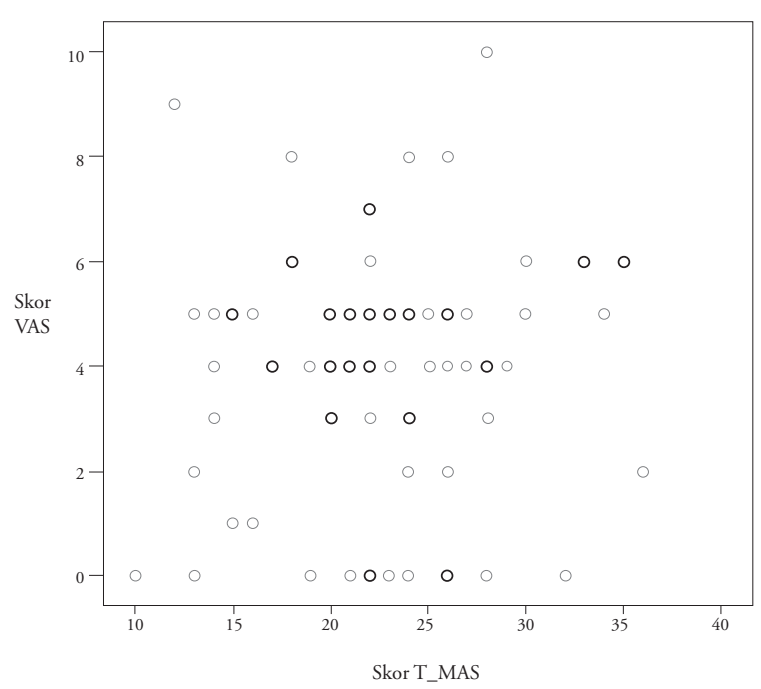

Gambar 1. Scatter plot hubungan antara skor T-MAS dan skor VAS

dismenore tidak memengaruhi jumlah subyek yang mencari pertolongan ( $\mathrm{p}=0,28$; RP 4,1 (IK 95\% 0,534)) (Tabel 3).

Data kualitatif yang didapatkan penulis menyebutkan bahwa sebagian besar remaja tetap melanjutkan aktifitas dengan atau tanpa memberikan terapi non medikamentosa (seperti obat gosok, minum hangat, minum jamu tradisional) untuk mengurangi rasa sakit akibat menstruasi. Para remaja ini berpendapat bahwa dismenore adalah suatu hal yang wajar terjadi pada wanita yang sedang menstruasi karena keluarga dan teman mereka juga mengalaminya, dapat berkurang dengan sendirinya tanpa pertolongan medis, dan baru perlu diperiksakan ke dokter jika keluhannya sangat berat dan berulang kali terjadi. Para remaja ini menyebutkan bahwa rasa cemas akan menstruasi tidak selalu terjadi saat menstruasi. Hal yang dicemaskan adalah menstruasi dapat mengganggu aktivitas seharihari akibat dari rasa nyeri, banyak darah yang keluar, dan gangguan emosi yang terjadi.

\section{Pembahasan}

Prevalensi dismenore pada remaja usia SMP di kota Surakarta cukup tinggi. Sebagian besar subyek masih dapat menjalankan aktifitas sehari-hari, dan tidak memerlukan terapi. Prevalensi dismenore yang tinggi juga ditunjukkan pada studi di Cina, yaitu 92,4\% subyek menderita dismenore ringan - berat, yang berdampak pada aktifitas mereka $(39,9 \%$ harus absen dari sekolah dan 49,8\% menggunakan analgetik 1-6 kali per siklus). ${ }^{5}$ Di Amerika Serikat, 14\%-52\% remaja tidak masuk sekolah karena dismenore). ${ }^{4}$ Lima puluh tiga persen remaja Australia mengalami penurunan aktifitas di sekolah, olahraga, dan sosial karena dismenore, dan $24 \%$ pekerja perempuan remaja harus absen tiap bulan karena dismenore ${ }^{3}$

Studi Alvin dan Litt (1982) (dikutip dari Jabbour $\mathrm{dkk}^{9}$ ) didapatkan, saat menstruasi terjadi progesterone withdrawal, yang memicu metabolisme asam arakhidonat dari membran fosfolipid menghasilkan prostaglandin (PGs) dan leukotrien (LTs). Adanya PGs dan LTs memicu respon inflamasi sehingga terjadi rasa sakit saat haid dan gejala sistemik yang dikenal dengan premenstrual syndrome. Penelitian Jabbour $\mathrm{dkk}^{9}(1982)$ terhadap cairan haid dari tampon ditemukan bahwa 
kadar PGF2 $\alpha$ - dua kali lebih tinggi pada wanita dismenore daripada eumenore. Penelitian Jabbour $\mathrm{dkk}^{9}$ (1982) mengenai leukotrien, menemukan korelasi yang erat antara LTC4 dan LTD4 pada aliran haid sesuai dengan beratnya dismenore pada wanita dengan dismenore primer.' Faktor risiko terkait dismenore antara lain adalah faktor demografi, lingkungan (stres fisik, polusi), kelainan organ obstetri ginekologi, dan problem psikososial. ${ }^{10}$ Berdasarkan hasil penelitian sebelumnya, disimpulkan bahwa angka dismenore yang tinggi pada remaja lebih disebabkan dari faktor patofisiologi yang mendasari dari adanya dismenore primer tersebut, dan faktor risiko dapat meningkatkan skor nyeri dari dismenore.

Skor kecemasan tinggi didapatkan pada 47,8\% subyek dengan rerata skor TMAS 22,7 $\pm 5,7$. Prevalensi kecemasan rendah pada remaja usia SMP di kota Surakarta masih lebih banyak didapatkan daripada kecemasan tinggi. Rerata skor kecemasan dalam perbatasan antara skor rendah dan tinggi. Pada penelitian lain, prevalensi kecemasan tinggi pada remaja berkisar antara 8\%-22\% dan 5,8\%-18,1\%. ${ }^{11,12}$

Kecemasan melibatkan perubahan otonom yang melibatkan perubahan hormonal dari aksis hipotalanus - hipofisis. Rerata skor T-MAS yang kami dapatkan menunjukkan bahwa kecemasan terdapat pada setiap individu dan diperlukan untuk pertahanan diri manusia terhadap stres. Terapi kecemasan diperlukan untuk kecemasan dengan skor tinggi atau kecemasan berlebihan yang menimbulkan gangguan. ${ }^{6,7}$

Hasil penelitian sebelumnya mengenai dismenore menyebutkan bahwa para remaja yang mengalami dismenore tidak mencari pertolongan, dan juga didapatkan dismenore tidak berkorelasi dengan pembatasan aktivitas. Para remaja tersebut mendapat informasi turun temurun mengenai menstruasi dari ibu atau neneknya. ${ }^{4,13}$ Dismenore sepertinya berkaitan dengan persepsi bahwa hal tersebut adalah hal yang biasa dan wajar terjadi karena keluarga atau teman dekat mereka juga mengalaminya.

Persepsi didefinisikan sebagai pengalaman sensorik terhadap dunia sekitar, meliputi pengenalan terhadap stimulus, dan reaksi terhadap stimulus yang terjadi. ${ }^{14}$ Persepsi dipengaruhi perceiver, obyek yang dipersepsikan, dan situasi yang terbentuk antara perceiver dan obyek, Faktor internal dari persepsi meliputi kebiasaan, motivasi, dan ketertarikan, pembelajaran, organisasi dan spesialisasi, ekonomi dan latar belakang sosial, dan personality. Sedangkan faktor external dari persepsi adalah intensitas, ukuran, kontras, pengulangan, pergerakan, novelty dan familiarity, dan situasi. ${ }^{14}$

Dalam kaitannya dengan ilmu sosiologi antropologi, faktor-faktor yang memengaruhi perilaku pencarian pertolongan kesehatan tehadap nyeri dismenore, antara lain pengalaman (pengalaman orang-orang disekitarnya bahwa dismenore tidak mengganggu aktivitas), persepsi (dismenore adalah hal yang biasa dan wajar terjadi), tingkat pengetahuan/ pemahaman (sehingga kurang dapat mengambil keputusan), motivasi (rasa ingin tahu kurang), kepercayaan (cenderung terapi alternatif), kemudahan mendapatkan pelayanan kesehatan (alasan biaya), dan tingkat sosial ekonomi (status sosial ekonomi kurang, tingkat pendidikan kurang, ketidakmampuan mengambil keputusan). ${ }^{15}$

Penyebab rendahnya remaja putri mencari pertolongan kesehatan untuk kasus dismenore karena informasi yang telah terbentuk sebelumnya dari lingkungan sekitar. Edukasi tepat oleh keluarga diperlukan agar para remaja putri tidak cenderung mengabaikan dismenore. Meskipun sebagian besar kasus dismenore pada remaja putri disebabkan oleh faktor intrinsik uterus dan berhubungan erat dengan ketidakseimbangan hormon steroid seks dan jarang disebabkan oleh kelainan organik pelvis (infeksi, endometriosis, adenomiosis, mioma uteri, tumor ovarium, atau polip endometrium), tetapi edukasi tepat diperlukan agar tidak menyebabkan keterlambatan diagnosis penyebab dismenore.

Pendidikan kesehatan mengenai menstruasi diharapkan memperbaiki dan menyamakan persepsi orangtua, remaja, dan petugas kesehatan bahwa menstruasi dan permasalahannya perlu diperhatikan agar tidak terjadi keterlambatan diagnosis penyebab dismenore.

Kelemahan penelitian kami adalah faktor risiko lain yang terlibat dalam dismenore, kecemasan, sikap, dan pengetahuan mengenai dismenore tidak banyak diteliti. Penelitian lebih lanjut diperlukan untuk mengetahui keterkaitan berbagai faktor risiko dengan tingginya prevalensi dismenore, tingkat kecemasan, dan perilaku pencarian pertolongan kesehatan terhadap masalah dismenore pada remaja di kota Surakarta. Karakteristik remaja perempuan di kota Surakarta (Indonesia) dibandingkan dengan remaja perempuan di negara lain, ditilik dari ilmu sosiologi dan antropologi kesehatan dalam kaitannya dengan 
perilaku terhadap masalah menstruasi, juga menarik untuk dilakukan penelitian lebih lanjut.

\section{Kesimpulan}

Delapan puluh tujuh koma tujuh persen remaja SMP di kota Surakarta mengalami dismenore, dan 47,8\% remaja SMP di kota Surakarta memiliki skor kecemasan yang tinggi. Kami tidak mendapatkan hubungan antara kecemasan dengan dismenore. Deskripsi mengenai faktor risiko terkait dengan dismenore, tingkat kecemasan, perilaku pencarian pertolongan kesehatan, dan karakteristik remaja terkait dismenore pada remaja perlu dilakukan penelitian lebih lanjut.

\section{Daftar pustaka}

1. Hillard. Dysmenorrheae. Pediatr Rev 2006;27: 64-71.

2. Proctor M, Farquhar C. Diagnosis and manajement of dysmenorrhea. BMJ 2006;332:1134-8.

3. Harel Z. A contemporary approach to dysmenorrhea in adolescent. Pediatr Drugs 2002;4:787-806.

4. French L. Dysmenorrhea in adolescents, diagnosis and treatment. Pediatr Drugs 2008;10:1-7.

5. Chen HM, Chen CH. Related factors and consequences of menstrual distress in adolescent girls with dysmenorrhea. Kaohsiung J Med Sci 2005;21:7-121.

6. Seligman MEP, Walker EF, Rosenham DL. Abnormal psychology. Edisi ke-4. New York: WW Norton and Company Inc; 2001.

7. Ohman A. Fear and anxiety: evolutionary, cognitive, and clinical perspectives. Dalam: M Leons, JM Haviland. Handbook of emotion. New York: The Guillford Press; 2000.h.573-93.

8. Wang L, Wang X, Wang W, Chen C, Ronnennberg AG, Guang W, Huang A, Fang Z, Zang T, Xu X. Stress and dysmenorrhea: a population based prospective study. Occup Environ Med 2004;61:1021-6.

9. Jabbour HN, Kelly RW, Fraser HM, Critchley HOD. Endocrine regulation of menstruation. Endocrine Rev 2006;27:17-46.

10. Latthe P, Mignini L, Gray R, Hills R, Khan K. Factors predisposing women to chronic pelvic pain: a systematic review. BMJ 2006;332:749-55.

11. Briesch AM, Sanetti LMH, Briesch JM. Reducing the prevalence of anxiety in children and adolescents: an evaluation of the evidence base for friends for life program. School Mental Health 2010;2:155-165.

12. Fisak BJ, Richard D. Mann A. The prevention of child and adolescent anxiety: a meta analytic review. Prev Sci 2011.

13. Lestari H, Metusala J, Suryanto DY. Gambaran dismenore pada remaja putri Sekolah Menengah Pertama di Manado. Sari Pediatri 2010;12:99-102.

14. Freeman WJ. The physiology of perception. Scientific American 1991;264:78-85.

15. Ratna W. Sosiologi dan antropologi kesehatan. Yogyakarta: Pustaka Rihama; 2010. 